\title{
Transparent Wood Prepared by Polymer Impregnation of Rubber Wood (Hevea brasiliensis Muell. Arg)
}

\begin{abstract}
Daran Yue, ${ }^{\mathrm{a}, *}$ Guohua Fu, ${ }^{\mathrm{b}}$ and Zhiyang Jin ${ }^{\mathrm{c}}$
Transparent wood (TW), a new type of composite material with good optical transmittance and excellent mechanical properties, has attracted great interest in recent years. In this study, a hydrogen peroxide strategy was used on rubber wood (Hevea brasiliensis Muell. Arg) to eliminate lignin and hemicellulose. Subsequently, delignified wood was combined with each of three impregnants of refractive index similar to that of cellulose to obtain transparent wood (TW). Impregnation with polyvinylpyrrolidone (PVP), polyvinyl alcohol (PVOH), and methyl methacrylate (MMA)) resulted in transparent woods, which were named PVP-DRW, PVOH-DRW, and PMMA-DRW, respectively. The micromorphologies, chemical compositions, thermal stabilities, chemical functional groups, optical transmittance, and mechanical properties of the raw RW and of each processed sample were characterized. The results showed that the optical transmittance of PVOH-DRW $(76.6 \%, \lambda=600 \mathrm{~nm}, d=0.70 \mathrm{~mm})$ was similar to that of PVP-DRW $(73.4 \%, \lambda=600 \mathrm{~nm}, d=0.74 \mathrm{~mm})$ and higher than that of PMMA-DRW $(64.6 \%, \lambda=600 \mathrm{~nm}, d=0.73 \mathrm{~mm})$, but PMMADRW had a higher mechanical strength (fracture strength of $230.14 \mathrm{MPa}$ ). Therefore, the preparation of transparent wood with RW as the substrate is expected to be a potential material candidate for high-strength composites.
\end{abstract}

Keywords: Transparent wood; Rubber wood; Optical properties; Mechanical properties

Contact information: a: Key Laboratory of Genetics and Germplasm Innovation of Tropical Special Forest Trees and Ornamental Plants, Ministry of Education/Engineering Research Center of Rare and Precious Tree Species in Hainan Province, College of Forestry, Hainan University, Haikou 570228, P.R. China; b: Management School of Hainan University, Haikou 570228, P.R. China; c: Mechanical and Electrical Engineering College, Hainan University, Haikou 570228, P.R. China;

* Corresponding author: yuedaran@163.com

\section{INTRODUCTION}

With the emergence of global climate change and energy depletion in the $21^{\text {st }}$ century, new, environmentally friendly materials in a variety of fields have attracted widespread attention (Habibi et al. 2010; Li et al. 2016; Zhu et al. 2016a). As one of the earliest materials used by human beings, wood has been widely used in the fields of architecture, furniture, heating, and decoration for millennia (Li et al. 2018b; Li et al. 2020). With its degradation, high bulk modulus, low toxicity, and low thermal conductivity, wood has been widely utilized in the fields of bionic intelligence, clean energy, and bioengineering ( $\mathrm{Li}$ et al. 2016). Transparent wood (TW), a new wood derivative, has become a research hotspot because of its high transmittance, low thermal conductivity, low density, and high toughness (Li et al. 2016, 2018a). Diverse wood species such as balsa, birch, pine, and basswood have been used as raw materials to prepare TW.

Rubber wood is the main trunk of Hevea brasiliensis Muell. Arg, also known as the arbor or big tree, within the family Euphorbiaceae (Jiang et al. 2020). Rubber wood is the 
by-product of rubber production and processing. Because of the periodicity of rubber production, the economic life of rubber wood is usually 25 to 30 years (Tuerxun et al. 2019). It is one of the most versatile light hardwoods. Rubber wood is widely used in furniture manufacturing, interior decoration, and combustion heat production. To broaden the applications of rubber wood, researchers have explored its use in preparation of woodplastic composites and nanocellulose (He et al. 2019).

TW is a new type of biomass composite material which has been decolorized and rendered transparent, while still showing excellent mechanical properties (Cai et al. 2020). Since the first report of transparent wood in 1992, much research has been undertaken regarding the preparation and functionalization of transparent wood (Fink 1992; Li et al. 2018a; Mi et al. 2020). In TW, fiber cells are arranged naturally along the growth direction, forming an interconnected network structure wall structure that is composed mainly of cellulose, hemicellulose, and lignin, along with other trace components (Moon et al. 2011; Zhu et al. 2014; Burgert et al. 2015). Due to the occurrence of lignin, tannin, pigment, and other light-absorbing substances in wood, wood usually appears brown (Li et al. 2016; Zhu et al. 2016b).

Chemical treatment of wood to remove lignin or chemicals in the lignin chromogenic group effectively reduces light absorption. The main decolorization methods include the chlorite method, sulfite method, and lignin retention method. The delignified wood is composed of hollow fibers forming a mesoporous structure. Finished TW is formed by filling with a material matching the refractive index of cellulose. Common impregnated polymers include polyvinylpyrrolidone (PVP) (Zhu et al. 2016c), polymethylmethacrylate (PMMA) (Li et al. 2016), epoxy resin (EP) (Zhu et al. 2016b), and polyvinyl alcohol (PVOH) (Mi et al. 2020). Because of its high transmittance, high haze, and excellent mechanical properties, TW has been widely used in energy-saving building materials, electronic devices, solar panels, etc. (Montanari et al. 2019).

In this study, hydrogen peroxide was used to remove lignin, and three types of TW were prepared by impregnation with PVP, PVOH, and PMMA. Through the characterization of micromorphology, chemical structure, thermal stability, optical properties, and mechanical properties, differences among the three kinds of TW were revealed, and it was found that transparent wood prepared by PMMA impregnation of RW has high mechanical properties. It provides a basis for the application of RW in highstrength materials.

\section{EXPERIMENTAL}

\section{Materials}

Rubber wood was obtained from Danzhou City, Hainan, China. The sample dimension was $30 \times 15 \mathrm{~mm}$, with a thickness of $0.5 \mathrm{~mm}$. All the wood chips were along the plane direction. Potassium hydroxide, glacial acetic acid, hydrogen peroxide, absolute ethanol, methyl methacrylate, and other chemicals were of analytical grade and used without further purification. 2,2'-Azobis (isobutyronitrile) was provided by the Fuchen Chemical Reagent Co., Ltd. (Tianjin, China). Polyvinylpyrrolidone (PVP) and polyvinyl alcohol (PVOH-210, Mw 67000) were purchased from Aladdin Reagent Co., Ltd. (Shang Hai, China). Methyl methacrylate (MMA) was supplied by Macklin Biochemical Co., Ltd. (Shang Hai, China). 


\section{Experimental Methods \\ Delignification}

Lignin was removed as reported previously (Frey et al. 2018). RW chips were mixed with a $20 \mathrm{wt} \% \mathrm{KOH}$ solution in a $\mathrm{RW} / \mathrm{KOH}$ solid-to-liquid ratio of $1 \mathrm{~g}: 4 \mathrm{~g}$ and stirred for $2 \mathrm{~h}$ (hours) at $100{ }^{\circ} \mathrm{C}$. Then the sample was washed with distilled water. $2 \mathrm{~g}$ of the sample was treated in $100 \mathrm{~mL}$ of a solution of $\mathrm{H}_{2} \mathrm{O}_{2}$ and $\mathrm{H}-\mathrm{Ac}$ (volume ratio $1: 1$ ) at $100{ }^{\circ} \mathrm{C}$ for $4 \mathrm{~h}$. After chemical treatment, the wood chips turned white. The obtained sample (named DRW) was washed thoroughly and then freeze-dried.

\section{Preparation of PVP transparent rubber wood}

PVP transparent rubber wood was prepared as described by Zhu et al. (2016b). Polyvinylpyrrolidone was dispersed in ethanol to prepare a $15 \%$ dispersion. DRW was added to a culture dish containing an appropriate PVP solution. The height reached by the solution in the dish was 15 to 20 times the thickness of the wood sample. The DRW/PVP system was held at an ambient vacuum for $10 \mathrm{~min}$ at room temperature. The impregnation process was repeated several times to ensure complete immersion. Finally, the DRW sample was treated at $60{ }^{\circ} \mathrm{C}$ for 24 h to obtain TW (PVP-DRW).

\section{Preparation of PVOH transparent rubber wood}

The powdered polymer was dissolved in distilled water at a $10 \mathrm{wt} . \%$ concentration at $60{ }^{\circ} \mathrm{C}$ to prepare the PVOH solution (Mi et al. 2020). The DRW was added to a culture dish containing PVOH solution, and the height reached by the solution in the dish was 15 to 20 times the thickness of the wood chip. The wood chip was then degassed and infiltrated at $900 \mathrm{~Pa}$. This process was repeated many times to ensure the full infiltration of the wood. Finally, it was transferred to the oven and dried at $60{ }^{\circ} \mathrm{C}$ for $24 \mathrm{~h}$. The transparent wood obtained was named PVOH-DRW.

\section{Preparation of PMMA transparent rubber wood}

MMA was prepolymerized at $75{ }^{\circ} \mathrm{C}$ for 15 min with $0.3 \%$ AIBN as the initiator. The preparation was quickly cooled to room temperature under ice bath conditions. The DRW was immersed in the prepolymer solution for infiltration. Infiltration for $10 \mathrm{~min}$ under a vacuum at room temperature was repeated many times until the sample was fully infiltrated. Finally, the fully infiltrated sample was placed between two glass slides, wrapped in aluminum foil, and then polymerized at $70{ }^{\circ} \mathrm{C}$ for $4 \mathrm{~h} \mathrm{(Li} \mathrm{et} \mathrm{al.} \mathrm{2016).} \mathrm{The}$ sample obtained was labeled PMMA-DRW.

\section{Chemical Composition}

The chemical components of the samples before and after lignin removal were determined in accordance with the standards of the Technical Association of Pulp and Paper Industry (TAPPI). The content of acid-insoluble lignin in each sample was determined by TAPPI T222 om-1102 (2011). Holocellulose, hemicellulose, and acellulose content were determined by TAPPI T 19 m-54 (2011), TAPPI T223 cm-10 (2010), and T429 cm-10 (2010).

\section{Microscopic Morphology}

The microscopic morphology of each sample was characterized using a scanning electron microscope (SEM; SU8010, Hitachi, Tokyo, Japan). Each cross-section was prepared by liquid nitrogen cooling fracturing. All samples were treated with gold spray. 


\section{Fourier-transform Infrared Spectroscopy}

The infrared spectra were recorded on a Magna-IR 560 E.S.P. instrument (Nicolet, Madison, WI, USA). The scanning range was 400 to $4000 \mathrm{~cm}^{-1}$, and the resolution was 4 $\mathrm{cm}^{-1}$.

\section{Thermogravimetry}

The thermal stability of each sample was studied using a TG209F1 instrument (Netzsch, Shanghai, China). Each thermal stability measurement was acquired over a temperature range of 30 to $700{ }^{\circ} \mathrm{C}$ at a rate of $10{ }^{\circ} \mathrm{C} / \mathrm{min}$ under nitrogen atmosphere.

\section{Optical Transmittance}

The transmittance of each sample at various wavelengths was measured by an ultraviolet-visible spectrophotometer over a wavelength range from 300 to $800 \mathrm{~nm}$.

\section{Mechanical Performance}

Tensile tests were carried out on each sample using a wood universal testing machine (100KN/AG-A10T, Daojin, Japan). The stretching speed was $2 \mathrm{~mm} / \mathrm{min}$. All the samples were placed at $50 \%$ humidity for $24 \mathrm{~h}$ at a temperature of $20{ }^{\circ} \mathrm{C}$. Each sample was cut into a strip $(5 \mathrm{~mm} \times 30 \mathrm{~mm})$ for testing.

\section{RESULTS AND DISCUSSION}

\section{Chemical Composition Analysis}

Table 1 shows the contents of each component before and after chemical treatment. Due to the presence of light-absorbing substances such as lignin, tannins, and pigments, as well as differences in refractive index among wood components, natural wood was opaque. Figure 1a shows that the RW was yellowish-brown. Hydrogen peroxide was used to remove light-absorbing substances such as lignin. After delignification, the shape of the wood chip was retained, but its color became white (Fig. 1d). Figure 1b-e shows that after delignification, the cell wall became thinner, and the structure became looser. To further demonstrate the detachment of lignin, the chemical components of RW and DRW were analyzed. As shown in Table 1, the lignin content decreased from $15.87 \%$ to $0.89 \%$, while the relative contents of holocellulose and $\alpha$-cellulose increased. Clearly, lignin was removed by chemical treatment.

Table 1. Chemical Components of RW and DRW

\begin{tabular}{|c|c|c|c|c|}
\hline Sample & Holocellulose (\%) & Lignin (\%) & Hemicellulose (\%) & a-cellulose (\%) \\
\hline RW & 77.38 & 15.87 & 21.51 & 50.71 \\
\hline DRW & 92.63 & 0.89 & 15.46 & 62.43 \\
\hline
\end{tabular}

Delignified wood was opaque due to light-scattering between the wood's internal structure and the air. The refractive index of the cell wall of delignified wood was 1.53 . To reduce the scattering of light through the delignified wood, the wood voids were filled with various polymers of refractive index matching that of delignified wood. The refractive indices of PVP $(n=1.53), \mathrm{PVOH}(n \approx 1.53$ to 1.54$)$, and PMMA $(n=1.50)$ are similar to that of delignified wood ( $\mathrm{Li}$ et al. 2018a). Three kinds of transparent wood were prepared 
via impregnation of delignified wood with these three polymers (Fig. 2a-c). Figures $2 \mathrm{~d}-\mathrm{f}$ clearly show that the polymer and DRW were successfully compounded. Despite the good adhesion of polymers and fiber cells in most areas, interface debonding did occur in some areas, and a small number of voids were apparent. This interface debonding may be attributed to the low interface compatibility between polymers and wood.

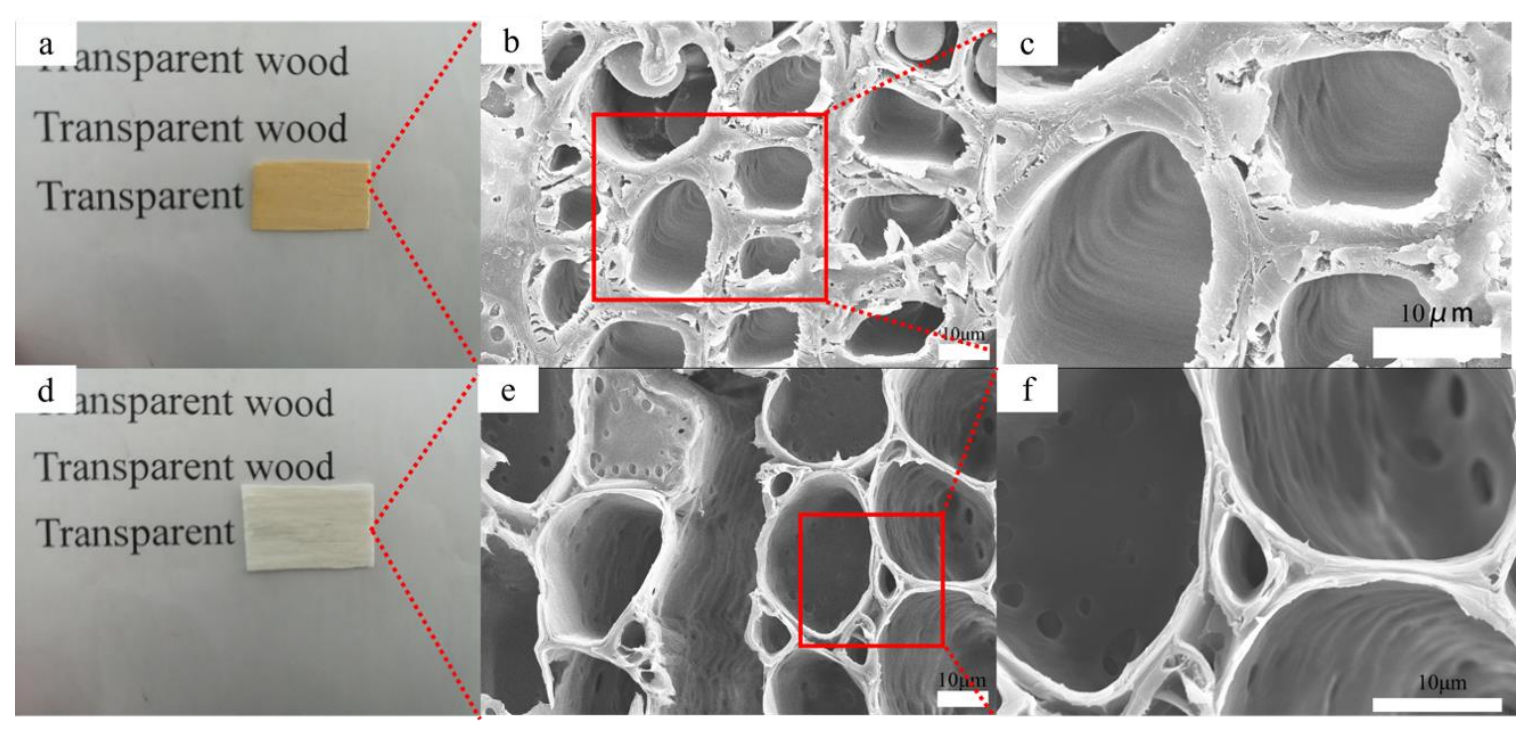

Fig. 1. Photographs and SEM images of $(a, b, c) R W$ and $(d, e, f) D R W$

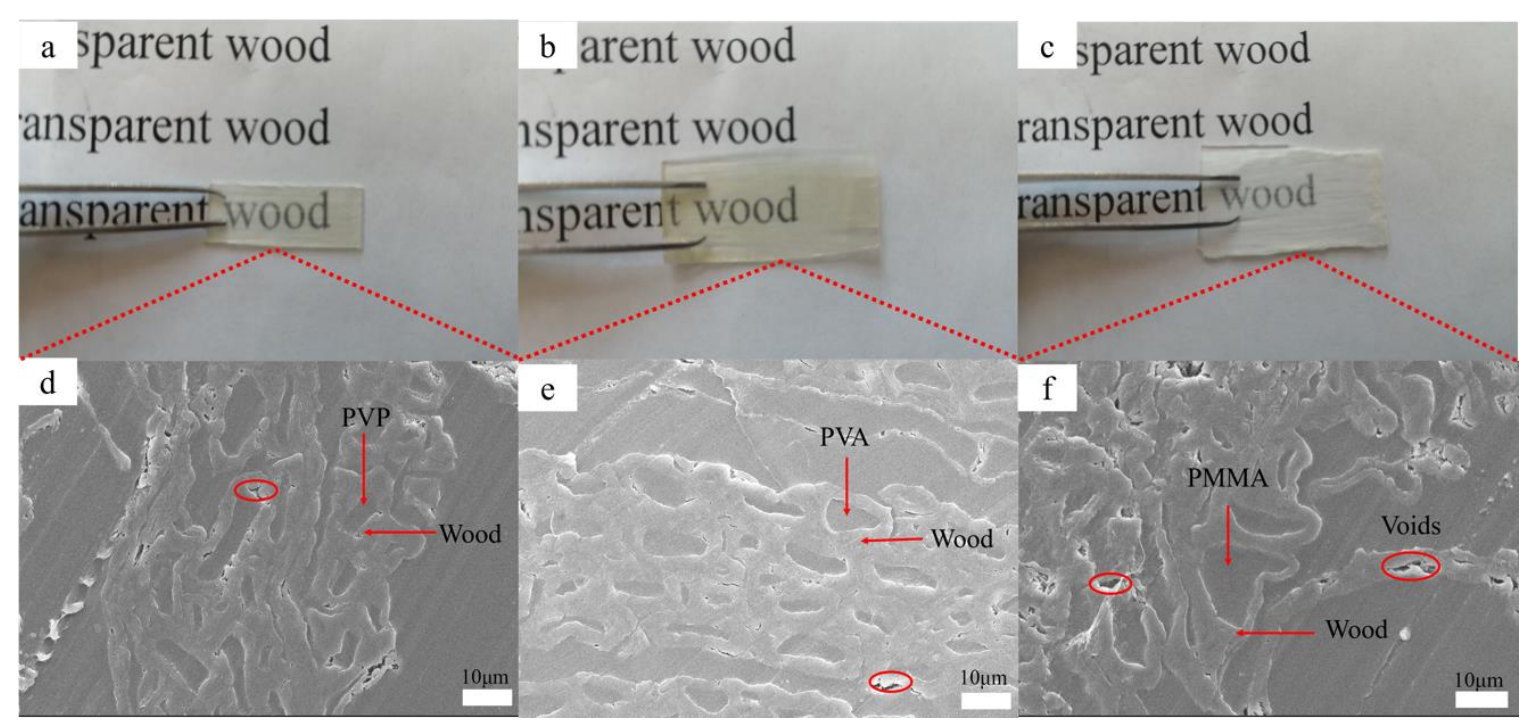

Fig. 2. Photographs and SEM images of (a, d) PVP-DRW, (b, e) PVOH-DRW and (c, f) PMMADRW

\section{Fourier-transform Infrared Analysis}

The FTIR spectra (Fig. 3) show changes in the chemical structure of samples. These changes were observed in the RW spectral band at $3340 \mathrm{~cm}^{-1}$ (O-H stretching), $2921 \mathrm{~cm}^{-1}$ (C-H stretching), $1740 \mathrm{~cm}^{-1}(\mathrm{C}=\mathrm{O}$ stretching in hemicellulose $), 1510 \mathrm{~cm}^{-1}(\mathrm{C}=\mathrm{C}$ stretching), and $1430 \mathrm{~cm}^{-1}$ (- $\mathrm{CH}_{2}$ bending) (Wu et al. 2019; Zhang et al. 2019). After chemical treatment, the peak at $1510 \mathrm{~cm}^{-1}$ indicated the removal of lignin, which was consistent with the chemical composition analysis. In PVP-DRW, the appearance of the 
characteristic peaks at $2952 \mathrm{~cm}^{-1}$ (C-H stretching), $1650 \mathrm{~cm}^{-1}$ ( $\mathrm{C}=\mathrm{O}$ stretching), $1425 \mathrm{~cm}^{-1}$ ( $\mathrm{C}=\mathrm{C}$ stretching), and $1290 \mathrm{~cm}^{-1}$ (C-N stretching) indicated that PVP successfully combined with DRW (Voronova et al. 2018). In PVOH-DRW, the characteristic peak at $3290 \mathrm{~cm}^{-1}$ was attributed to the stretching vibration of O-H. The characteristic peak at 1730 $\mathrm{cm}^{-1}$ was assigned to the stretching vibration of the polyvinyl acetate group. The $1374 \mathrm{~cm}^{-1}$ and $1095 \mathrm{~cm}^{-1}$ peaks corresponded to the stretching vibrations of $\mathrm{CH}-\mathrm{OH}$ and $\mathrm{C}-\mathrm{O}$, respectively (Abou Taleb et al. 2009). In PMMA-DRW, the characteristic peaks at 2996 $\mathrm{cm}^{-1}$ and $2950 \mathrm{~cm}^{-1}$ were attributed to C-H stretching vibrations, while the $1740 \mathrm{~cm}^{-1}$ peaks were designated as a $\mathrm{C}=\mathrm{O}$ stretching vibration. Then, the saturated $\mathrm{C}-\mathrm{H}$ bending vibration was attributed at $1440 \mathrm{~cm}^{-1}$. The $1190 \mathrm{~cm}^{-1}$ and $1140 \mathrm{~cm}^{-1}$ peaks were derived from C-O vibration (Jiang et al. 2013; Wu et al. 2019).

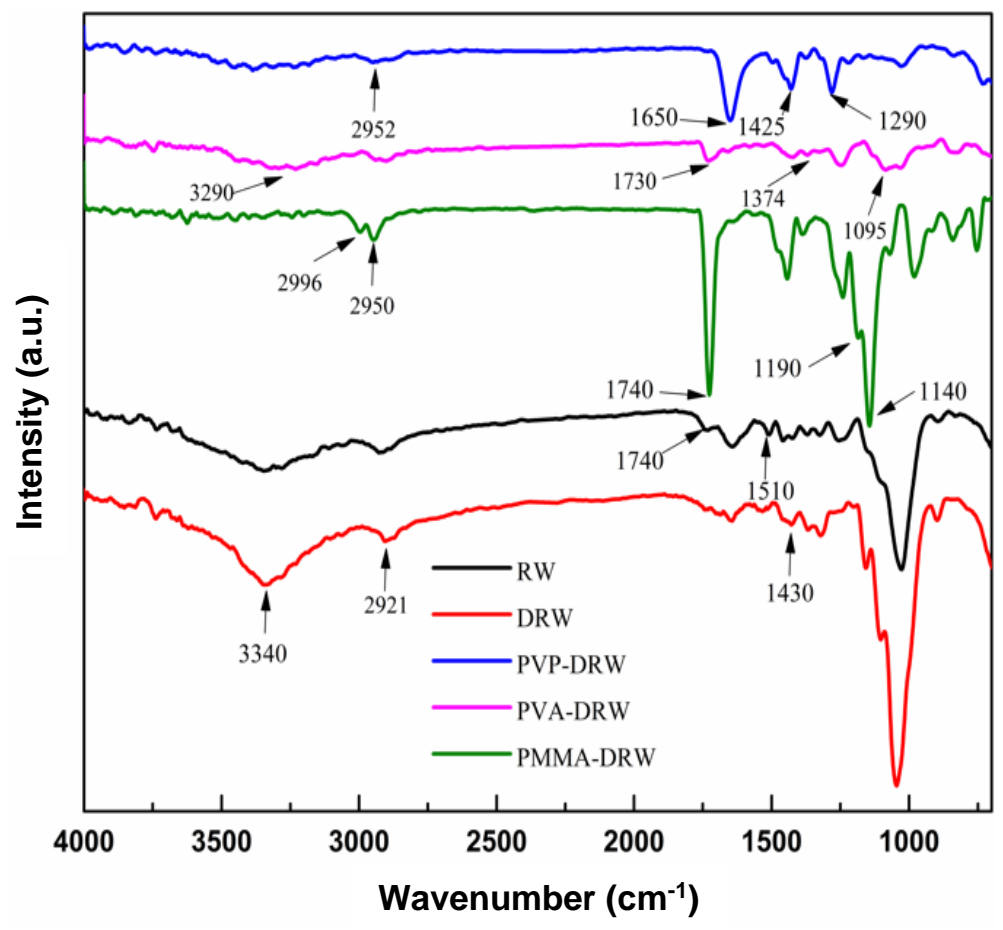

Fig. 3. FTIR spectra of RW, DRW, PVP-DRW, PVOH-DRW, and PMMA-DRW

\section{Thermal Stability}

The thermogravimetric analysis is shown in Fig. 4. RW and DRW showed a slight mass loss below $150{ }^{\circ} \mathrm{C}$, caused by loss of the absorbed water in the sample. The first pyrolysis in wood is that of hemicellulose $\left(180\right.$ to $\left.350{ }^{\circ} \mathrm{C}\right)$, followed by the degradations of cellulose $\left(275\right.$ to $\left.350{ }^{\circ} \mathrm{C}\right)$. Lignin showed better thermal stability $\left(250\right.$ to $\left.500{ }^{\circ} \mathrm{C}\right)$ than cellulose or hemicellulose due to its higher molecular weight and crosslinking degree (Kim et al. 2006; Poletto et al. 2012). RW was no exception. The second degradation stage of RW occurred due to the decomposition of hemicellulose, cellulose, and lignin, and the maximum degradation rate was observed at $336^{\circ} \mathrm{C}$. The delignified DRW samples showed a higher pyrolysis rate. At $375{ }^{\circ} \mathrm{C}$, the pyrolysis rate for DRW reached its maximum $(22.38 \% / \mathrm{min})$, which was approximately 2.7 times that of $\mathrm{RW}(8.30 \% / \mathrm{min})$. There was a slight mass loss of PVP-DRW at $100{ }^{\circ} \mathrm{C}$, related to the evaporation of water. The small peak at $360{ }^{\circ} \mathrm{C}$ was due to the degradation of cellulose, and the maximum decomposition rate at $435{ }^{\circ} \mathrm{C}$ was caused by the degradation of PVP (Bianco et al. 2003). The thermal 
stability of PVP-DRW was improved after PVP impregnation. The PVOH-DRW degradation diagram makes clear that the degradation around $320{ }^{\circ} \mathrm{C}$ was caused by the breakage of the PVOH side group and the degradation of cellulose, and the PVOH skeleton decomposition near $434{ }^{\circ} \mathrm{C}$ (Voronova et al. 2015). During the thermal degradation of PMMA-DRW, the thermal degradation occurring below $300{ }^{\circ} \mathrm{C}$ was caused by the cleavage of the $\mathrm{C}-\mathrm{C}$ bond at the end of the PMMA chain. The maximum pyrolysis rate reached at $380{ }^{\circ} \mathrm{C}$ was due to the degradation of cellulose and the irregular breakage of $\mathrm{C}$ C bonds in the PMMA backbone (Montanari et al. 2019; Kim et al. 2020).
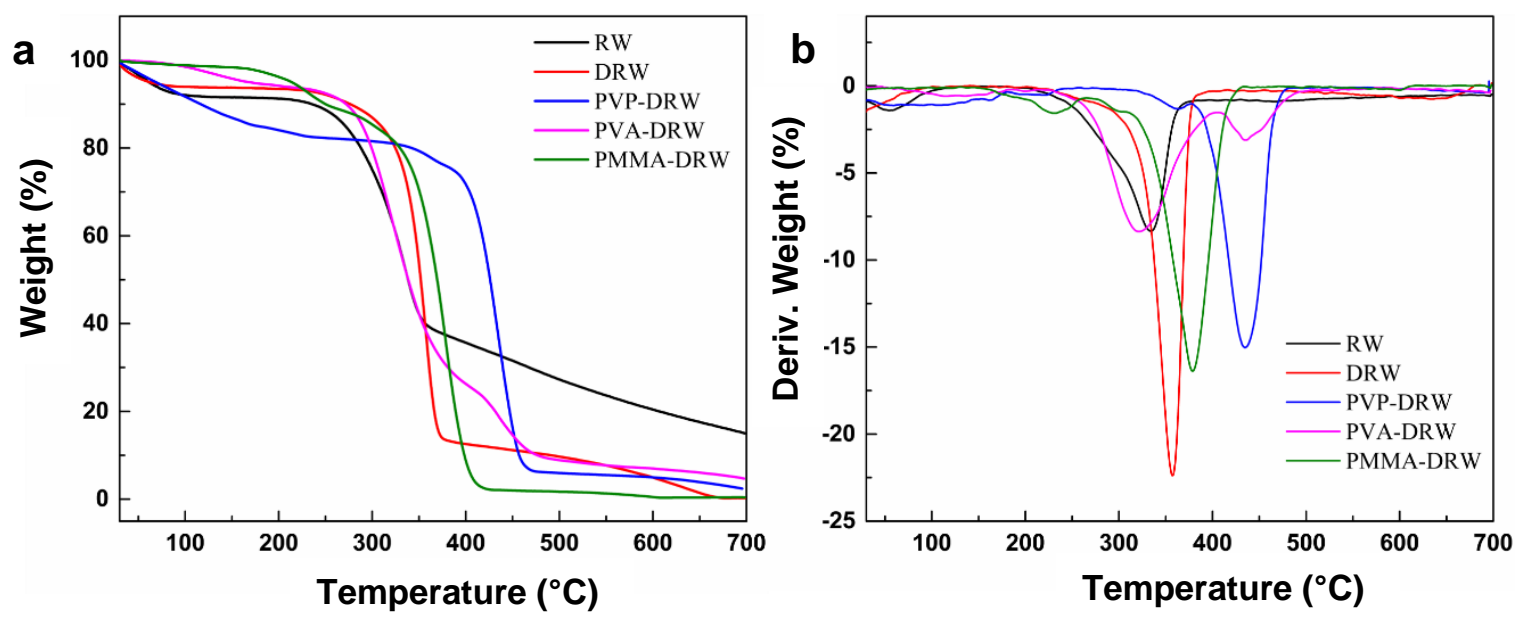

Fig. 4. (a) TG and (b) DTG curves of RW, DRW, PVP-DRW, PVOH-DRW, and PMMA-DRW

\section{Optical Properties}

The optical properties of each sample were evaluated by recording the transmittance of the sample in the visible wavelength range (300 to $800 \mathrm{~nm}$ ). Figure 5 shows that the transmittance of RW with a thickness of $0.5 \mathrm{~mm}$ is $4.3 \%$ at $600 \mathrm{~nm}$, which is due to the presence of lignin and other light-absorbing substances in natural wood.

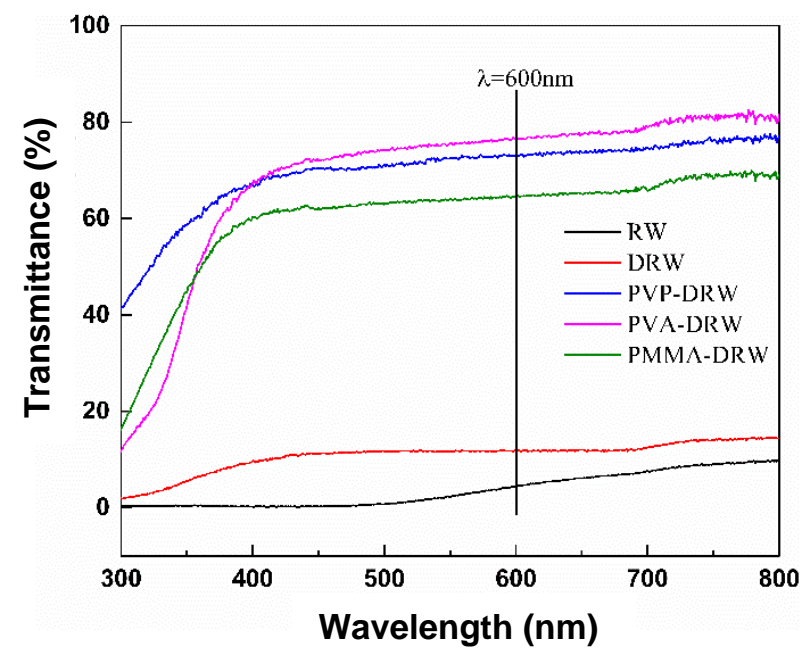

Fig. 5. Optical transmittance of RW, DRW, PVP-DRW, PVOH-DRW, and PMMA-DRW

However, after the removal of lignin, the transmittance of RW grows to $11.8 \%$ and its thickness becomes $0.82 \mathrm{~mm}$. This phenomenon was due to the removal of lignin and 
light-absorbing substances, which makes the tissue structure of wood chips more sparse, and the presence of mesoporous structure in the DRW, which caused the incident light to scatter on the hollow interface. The DRW was filled with a polymer matching the refractive index of DRW $(n \approx 1.53)$ : $\mathrm{PVP}(n \approx 1.53)$, $\mathrm{PVOH}(n \approx 1.54)$, or PMMA $(n \approx 1.50)$. The transmittances of PVP-DRW, PVOH-DRW, and PMMA-DRW at $\lambda=600 \mathrm{~nm}$ were obtained after polymer infiltration of $73.4 \%(d=0.74 \mathrm{~mm}), 76.6 \%(d=0.70 \mathrm{~mm})$, and $64.6 \%$ ( $d=0.73 \mathrm{~mm}$ ), respectively. All three types of transparent wood exhibited good transmittance, with PVP-DRW and PVOH-DRW having higher transmittance, which may be attributed to their refractive indices being more compatible with the wood. In contrast, the lower transparency of PMMA-DRW may be due to a lack of interfacial compatibility present in PMMA and DRW, which is consistent with the results of morphology analysis.

\section{Mechanical Properties}

The mechanical properties of the samples were characterized with a universal material testing machine (Fig. 6). In transparent wood, the composition, structure, and volume fraction of the matrix and reinforing materials have a strong influence on its mechanical properties (Jungstedt et al. 2020). Compared with RW (fracture strength of 40.22 MPa, elastic modulus of $5.91 \mathrm{GPa}$ and $\rho=0.68 \mathrm{~g} / \mathrm{cm}^{3}$ ), the tensile strength and modulus of DRW obtained by delignification were $6.44 \mathrm{MPa}$ and $0.81 \mathrm{GPa}$, respectively. Then, the DRW density changed to $0.32 \mathrm{~g} / \mathrm{cm}^{3}$. This is due to increase in cell wall micronanostructures after lignin removal and the lack of inter-nanofiber strong load transfer mechanical. However, the tensile strength of TW obtained by impregnation of various polymers was greatly improved. PMMA-DRW showed the best mechanical properties (fracture strength of $230.14 \mathrm{MPa}$, modulus of $12.31 \mathrm{GPa}$ and $v_{\mathrm{f}}=19 \%$ ), higher than those of PVP-DRW (fracture strength of $96.79 \mathrm{MPa}$, modulus of $7.03 \mathrm{GPa}$ and $v_{\mathrm{f}}=22 \%$ ) or PVOH-DRW (fracture strength of $164.32 \mathrm{MPa}$ and modulus of $11.08 \mathrm{GPa}$ and $v_{\mathrm{f}}=25 \%$ ) and about 5.7 times those of RW. Compared with other species of TW, PMMA-DRW demonstrated higher strength (Fig. 6b), which may be attributed to the high density of the RW substrate, resulting in a good synergy between PMMA and DRW templates. (Li et al. 2016; Yaddanapudi et al. 2017; Lang et al. 2018). The mechanical properties of all three types of wood were improved by the delignification-impregnation process.

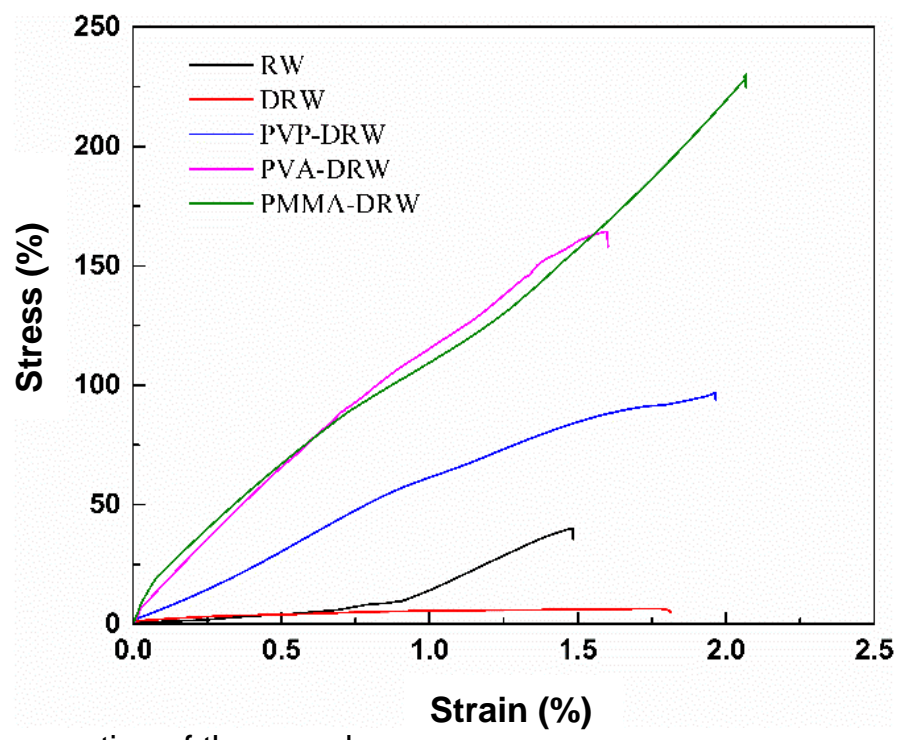

Fig. 6. Mechanical properties of the samples 


\section{CONCLUSIONS}

1. For the first time, three kinds of transparent wood (PVP-DRW, PVOH-DRW, and PMMA-DRW) were successfully prepared using rubber wood as the substrate. The optical transmittances of PVP-DRW, PVOH-DRW, and PMMA-DRW at a wavelength of $600 \mathrm{~nm}$ were $73.4 \%, 76.6 \%$, and $64.6 \%$, respectively. Scanning electron microscopy (SEM), Fourier transform infrared (FTIR) spectrometry, and thermogravimetric (TG) analysis results further confirmed the successful preparation of transparent wood and performance differences among the three transparent woods (TWs).

2. Impregnation of the delignified wood with each of the three polymers greatly improved the tensile strength of the wood, with PMMA-DRW (230.14 MPa) exhibiting a tensile strength of 5.7 times that of the original rubber wood (RW). TW made from RW had better mechanical properties than TW made from other species, which may be due to the hard texture and higher density of RW.

3. The observed excellent mechanical properties make RW a promising material with great prospects for smart buildings, aerospace, clean energy, etc.

\section{ACKNOWLEDGMENTS}

The author thanks Hainan University, Key Laboratory of Genetics and Germplasm Innovation of Tropical Special Forest Trees and Ornamental Plants and Ministry of Education/Engineering Research Center of Rare and Precious Tree Species in Hainan Province for their full support. The author declares no conflict of interest. This research was funded by the Natural Science Foundation of Hainan Province (319QN168) and the Research Startup Fund of Hainan University (KYQD(ZR)1986).

\section{REFERENCES CITED}

Abou Taleb, M. F., El-Mohdy, H. L. A., and El-Rehim, H. A. A. (2009). "Radiation preparation of PVA/CMC copolymers and their application in removal of dyes," Journal of Hazardous Materials 168(1), 68-75. DOI: 10.1016/j.jhazmat.2009.02.001

Bianco, G., Soldi, M. S., Pinheiro, E. A., Pires, A. T. N., Gehlen, M. H., and Soldi, V. (2003). "Thermal stability of poly(N-vinyl-2-pyrrolidone-co-methacrylic acid) copolymers in inert atmosphere," Polymer Degradation and Stability 80(3), 567-574. DOI: $10.1016 / \mathrm{s} 0141-3910(03) 00053-3$

Burgert, I., Cabane, E., Zollfrank, C., and Berglund, L. (2015). "Bio-inspired functional wood-based materials - Hybrids and replicates," International Materials Reviews 60(8), 431-450. DOI: 10.1179/1743280415y.0000000009

Cai, H., Wang, Z., Xie, D., Zhao, P., Sun, J., Qin, D., and Cheng, F. (2020). "Flexible transparent wood enabled by epoxy resin and ethylene glycol diglycidyl ether," Journal of Forestry Research. DOI: 10.1007/s11676-020-01201-y

Fink, S. (1992). "Transparent wood - A new approach in the functional study of wood structure," Holzforschung 46(5), 403-408. DOI: 10.1515/hfsg.1992.46.5.403

Frey, M., Widner, D., Segmehl, J. S., Casdorff, K., Keplinger, T., and Burgert, I. (2018). "Delignified and densified cellulose bulk materials with excellent tensile properties 
for sustainable engineering," ACS Applied Materials \& Interfaces 10(5), 5030-5037. DOI: 10.1021/acsami.7b18646

Habibi, Y., Lucia, L. A., and Rojas, O. J. (2010). "Cellulose nanocrystals: chemistry, selfassembly, and applications," Chemical Reviews 110(6), 3479-3500. DOI: $10.1021 / \mathrm{cr} 900339 \mathrm{w}$

He, T. S., Xu, R. S., Da, Y. Q., Yang, R. H., Chen, C., and Liu, Y. (2019). "Experimental study of high-performance autoclaved aerated concrete produced with recycled wood fibre and rubber powder," Journal of Cleaner Production 234, 559-567. DOI: 10.1016/j.jclepro.2019.06.276

Jiang, H., Quanji, L. U., Guanjun, L. I., Min, L. I., and Jianing, L. I. (2020). "Effect of heat treatment on the surface color of rubber wood (Hevea brasiliensis)," Wood Research 65(4), 633-644. DOI: 10.37763/wr.1336-4561/65.4.633644

Jiang, S. H., Gui, Z., Bao, C. L., Dai, K., Wang, X., Zhou, K. Q., Shi, Y. Q., Lo, S. M., and $\mathrm{Hu}, \mathrm{Y}$. (2013). "Preparation of functionalized graphene by simultaneous reduction and surface modification and its polymethyl methacrylate composites through latex technology and melt blending," Chemical Engineering Journal 226, 326-335. DOI: 10.1016/j.cej.2013.04.068

Jungstedt, E., Montanari, C., Ostlund, S., and Berglund, L. (2020). "Mechanical properties of transparent high strength biocomposites from delignified wood veneer." Composites Part A - Applied Science and Manufacturing 133. DOI: 10.1016/j.compositesa.2020.105853

Kim, D. W., Shin, J., and Choi, S. Q. (2020). "Nano-dispersed cellulose nanofibrilsPMMA composite from pickering emulsion with tunable interfacial tensions," Carbohydrate Polymers 247, 116762. DOI: 10.1016/j.carbpol.2020.116762

Kim, H. S., Kim, S., Kim, H. J., and Yang, H. S. (2006). "Thermal properties of bioflour-filled polyolefin composites with different compatibilizing agent type and content," Thermochimica Acta 451(1-2), 181-188. DOI: 10.1016/j.tca.2006.09.013

Lang, A. W., Li, Y., De Keersmaecker, M., Shen, D. E., Osterholm, A. M., Berglund, L., and Reynolds, J. R. (2018). "Transparent wood smart windows: Polymer electrochromic devices based on poly(3,4-ethylenedioxythiophene):poly(styrene sulfonate) electrodes," Chemsuschem 11(5), 854-863. DOI: 10.1002/cssc.201702026

Li, W., Chen, Z. J., Yu, H. P., Li, J., and Liu, S. X. (2020). "Wood-derived carbon materials and light-emitting materials," Advanced Materials 2000596. DOI: 10.1002/adma.202000596

Li, Y., Fu, Q., Yu, S., Yan, M., and Berglund, L. (2016). "Optically transparent wood from a nanoporous cellulosic template: Combining functional and structural performance," Biomacromolecules 17(4), 1358-1364. DOI: 10.1021/acs.biomac.6b00145

Li, Y., Vasileva, E., Sychugov, I., Popov, S., and Berglund, L. (2018a). "Optically transparent wood: Recent progress, opportunities, and challenges," Advanced Optical Materials 6(14), 1800059. DOI: 10.1002/adom.201800059

Li, Y., Yang, X., Fu, Q., Rojas, R., Yan, M., and Berglund, L. (2018b). "Towards centimeter thick transparent wood through interface manipulation," Journal of Materials Chemistry A 6(3), 1094-1101. DOI: 10.1039/c7ta09973h

Mi, R., Li, T., Dalgo, D., Chen, C., Kuang, Y., He, S., Zhao, X., Xie, W., Gan, W., Zhu, J., Srebric, J., Yang, R., and Hu, L. (2020). "A clear, strong, and thermally insulated transparent wood for energy efficient windows," Advanced Functional Materials 30(1), 1907511. DOI: 10.1002/adfm.201907511 
Montanari, C., Li, Y., Chen, H., Yan, M., and Berglund, L. A. (2019). "Transparent wood for thermal energy storage and reversible optical transmittance," ACS Applied Materials \& Interfaces 11(22), 20465-20472. DOI: 10.1021/acsami.9b05525

Moon, R. J., Martini, A., Nairn, J., Simonsen, J., and Youngblood, J. (2011). "Cellulose nanomaterials review: Structure, properties and nanocomposites," Chemical Society Reviews 40(7), 3941-3994. DOI: 10.1039/c0cs00108b

Poletto, M., Zattera, A. J., Forte, M. M. C., and Santana, R. M. C. (2012). "Thermal decomposition of wood: Influence of wood components and cellulose crystallite size," Bioresource Technology 109, 148-153. DOI: 10.1016/j.biortech.2011.11.122

TAPPI T223 cm-10 (2010). "Pentosans in wood and pulp," TAPPI Press, Atlanta, GA, USA.

TAPPI T222 om-11 (2011). “Acid-insoluble lignin in wood and pulp," TAPPI Press, Atlanta, GA, USA.

TAPPI T19 m-54 (2011). "Holocellulose in wood," TAPPI Press, Atlanta, GA, USA.

TAPPI T429 cm-10 (2010). "Alpha-cellulose in paper," TAPPI Press, Atlanta, GA, USA.

Tuerxun, D., Pulingam, T., Nordin, N. I., Chen, Y. W., Bin Kamaldin, J., Julkapli, N. B. M., Lee, H. V., Leo, B. F., and Bin Johan, M. R. (2019). "Synthesis, characterization and cytotoxicity studies of nanocrystalline cellulose from the production waste of rubber-wood and kenaf-bast fibers," European Polymer Journal 116, 352-360. DOI: 10.1016/j.eurpolymj.2019.04.021

Voronova, M., Rubleva, N., Kochkina, N., Afineevskii, A., Zakharov, A., and Surov, O. (2018). "Preparation and characterization of polyvinylpyrrolidone/cellulose nanocrystals composites," Nanomaterials 8(12). DOI: 10.3390/nano8121011

Voronova, M. I., Surov, O. V., Guseinov, S. S., Barannikov, V. P., and Zakharov, A. G. (2015). "Thermal stability of polyvinyl alcohol/nanocrystalline cellulose composites," Carbohydrate Polymers 130, 440-447. DOI: 10.1016/j.carbpol.2015.05.032

Wu, J., Wu, Y., Yang, F., Tang, C., Huang, Q., and Zhang, J. (2019). "Impact of delignification on morphological, optical and mechanical properties of transparent wood," Composites Part A - Applied Science and Manufacturing 117, 324-331. DOI: 10.1016/j.compositesa.2018.12.004

Yaddanapudi, H. S., Hickerson, N., Saini, S., and Tiwari, A. (2017). "Fabrication and characterization of transparent wood for next generation smart building applications," Vacuum 146, 649-654. DOI: 10.1016/j.vacuum.2017.01.016

Zhang, T., Yang, P., Chen, M., Yang, K., Cao, Y., Li, X., Tang, M., Chen, W., and Zhou, X. (2019). "Constructing a novel electroluminescent device with high-temperature and high-humidity resistance based on a flexible transparent wood film," ACS Applied Materials \& Interfaces 11(39), 36010-36019. DOI: 10.1021/acsami.9b09331

Zhu, H. L., Fang, Z. Q., Preston, C., Li, Y. Y., and Hu, L. B. (2014). "Transparent paper: fabrications, properties, and device applications," Energy \& Environmental Science 7(1), 269-287. DOI: 10.1039/c3ee43024c

Zhu, H., Luo, W., Ciesielski, P. N., Fang, Z., Zhu, J. Y., Henriksson, G., Himmel, M. E., and $\mathrm{Hu}, \mathrm{L}$. (2016a). "Wood-derived materials for green electronics, biological devices, and energy applications," Chemical Reviews 116(16), 9305-9374. DOI: 10.1021/acs.chemrev.6b00225

Zhu, M. W., Li, T., Davis, C. S., Yao, Y. G., Dai, J. Q., Wang, Y. B., AlQatari, F., Gilman, J. W., and Hu, L. B. (2016b). "Transparent and haze wood composites for highly efficient broadband light management in solar cells," Nano Energy 26, 332339. DOI: 10.1016/j.nanoen.2016.05.020 
Zhu, M. W., Song, J. W., Li, T., Gong, A., Wang, Y. B., Dai, J. Q., Yao, Y. G., Luo, W., Henderson, D., and Hu, L. B. (2016c). "Highly anisotropic, highly transparent wood composites," Advanced Materials 28(26), 5181-5187. DOI:

10.1002/adma.201600427

Article submitted: November 25, 2020; Peer review completed: January 10, 2021;

Revised version received and accepted: February 9, 2021; Published: February 11, 2021.

DOI: $10.15376 /$ biores.16.2.2491-2502 